\title{
Four or More Species of Cladosporium Sympatrically Colonize Phragmites australis
}

\author{
Stefan G. R. Wirsel,* Christiane Runge-Froböse,* Dag G. Ahrén,† \\ Eric Kemen,* Richard P. Oliver, $\neq$ and Kurt W. Mendgen*,1
}

*Lehrstuhl für Phytopathologie, Fachbereich Biologie, Universität Konstanz, Universitätstr. 10, 78457 Konstanz, Germany; † M icrobial Ecology, Ecology Building, Lund University, 22362 Lund, Sweden; and $¥$ Australian Centre for Necrotrophic Fungal Pathogens, School of B iological Sciences, M urdoch University, Perth,

Western Australia 6150, Australia

Accepted for publication November 8, 2001; published online J anuary 24, 2002

Wirsel, S. G. R., Runge-Froböse, C., Ahrén, D. G., Kemen, E., Oliver, R. P., and Mendgen, K. W. 2002. Four or more species of Cladosporium sympatrically colonize Phragmites australis. Fungal Genetics and Biology 35, 99-113. A collection of Cladosporium has been recovered from common reed growing at Lake Constance (Germany). High-resolution cryoscanning electron microscopy revealed that Cladosporium isolates from reed are diverse. Morphologically, we distinguished three species, viz. $C$. herbarum, $C$. oxysporum, and Cladosporium sp. Internal transcribed spacer (ITS) sequence analysis supported these results and, moreover, separated the most common species, C. oxysporum, into two subclades. Two additional phylogenies were generated to gain support for this finding. The first, differentiating fungi by their capacities to metabolize different carbon sources, showed correlation with morphology. The second, based on actin gene sequences, showed the same overall topology as that of the ITS tree, but resulted in a higher resolution indicating the existence of four or more species of Cladosporium on reed. A nested PCR assay targeting variable sequences within actin introns indicated that these four species sympatrically colonize reed. There was no evidence for mutual exclusion on or within the host or specialization for host habitats or organs. $\quad 2002$ Elsevier Science (USA)

\footnotetext{
${ }^{1}$ To whom correspondence should be addressed. F ax: $(+49) 7531$ 883035. E-mail: kurt.w.mendgen@uni-konstanz.de.
}

Index Descriptors: Cladosporium; Septoria; Mycosphaerella; reed; Phragmites australis; Actin; ITS; BIOLOG.

As part of a long-term program designed to integrate several aspects of freshwater ecology at Lake Constance (Germany), we have investigated the interaction of fungi with common reed (Phragmites australis (Cav.) Trin. ex Steudel, Poaceae) and their influence on the productivity and health of the host. Reed is a wetland plant that can form homogenous belts around freshwater lakes. In an earlier report, we described a collection of reed-associated fungi obtained during a study designed to identify specialization toward the host organ and/or the position of the host within the reed belt (Wirsel et al., 2001). These isolates were recovered from surface-sterilized root, stem, and leaf samples and were classified by morphological traits at the genus level. For each group, we determined the internal transcribed spacer (ITS) sequence of one or two isolates which confirmed the morphological grouping in most cases.

$\mathrm{H}$ ere, we analyze in detail the taxonomy, physiology, and ecology of one of the most common genera from that collection, Cladosporium, which represented about 15\% of all isolates. The anamorph genus Cladosporium is one of the most widespread and prevalent of all fungal genera (D avid, 1997). It lacks morphological structures that would firmly place species in an evolutionary context. M olecular data are therefore important to reveal phyloge- 
netic relationships within this genus. In an earlier study (Curtis et al., 1994) partial rDNA sequences of several independent isolates of $C$. fulvum (syns. Fulvia fulva, $M$ ycovellosiella fulva) and single isolates of $C$. herbarum, C. oxysporum, C. cladosporioides, and C. sphaerospermum indicated that these species together might form a monophyletic clade. Where it is known, species of Cladosporium have Mycosphaerella (M ycosphaerellaceae, D othideales) teleomorphs. M ycosphaer ella is also a large genus containing many important plant pathogens, such as M. graminicola (anamorph: Septoria tritici), which is a serious wheat pathogen.

The present study addresses three questions about the ecology of reed-associated Cladosporia. First, do all isolates studied belong to one or more species? This problem was approached by a scanning electron microscopy (SE M )-enhanced morphological characterization and by building a molecular phylogeny based on the ITS region and the actin gene. Second, is there a specialization for host habitat and/or organ? This hypothesis was investigated by correlating carbon utilization patterns obtained from BIOLOG microtiter plates with sampling data and by comparing the most parsimonious actin/lTS tree with several constrained trees that grouped strains according to sampling details. Third, is there evidence for mutual exclusion of the four different clades of Cladosporia on reed? F or this purpose we developed a nested PCR assay based on divergent actin gene sequences that differentially detects different taxa in environmental D NA.

\section{MATERIALS AND METHODS}

\section{Plant and Fungal Materials}

The fungal isolates used in this study (Table 1 ) originate from a sampling program at two locations $6.8 \mathrm{~km}$ apart at opposite shores of the Bodman peninsula at Lake Constance (Germany) (Wirsel et al., 2001). At each location, two reed habitat types, separated by about $50 \mathrm{~m}$, were sampled. One type was at the lakeward side of the reed belt and was permanently flooded under normal water levels ("flooded site"). The other was at the landward side of the reed belt and only flooded during extreme highwater periods ("dry site"). R eference cultures are listed in Table 2. F ungi were grown on $2 \%$ malt agar (Biomalt; Villa $\mathrm{N}$ atura Gesundprodukte $\mathrm{G} \mathrm{mbH}, \mathrm{K}$ irn, Germany) at $22^{\circ} \mathrm{C}$ under long-wave UV light. Representative isolates described in this work were deposited at CBS (Utrecht, $\mathrm{N}$ etherlands).
Clumps of three to five culms-including their root systems-that covered a surface area of about $30 \times 30 \mathrm{~cm}$ were dug out in August 1998, August 1999, and A pril 2000 at the same four sites at $L$ ake $C$ onstance described above. The April harvests represented young shoots of about 20 $\mathrm{cm}$ height, whereas the August samples represented the peak biomass. We divided the August plants into root, stem, and leaf samples, whereas the April plants were divided into root and shoot samples, the latter comprising stems and unfolded leaves. All samples were thoroughly washed under running tap water and stored at $-70^{\circ} \mathrm{C}$ until DNA isolation.

\section{Low-Temperature Scanning Electron Microscopy (LTSEM)}

Fungal samples were taken from malt agar cultures (approx. $4 \mathrm{~mm}^{2}$ ), mounted on aluminum stubs with Tissue-tek (Sakura, Tokyo, Japan) and frozen by plunging holder and sample into nitrogen slush. Samples were then inserted into the Alto 2500 (G atan, Oxford, U.K.) preparation chamber by means of the vacuum transfer device and mounted onto the cryostage cooled to $-130^{\circ} \mathrm{C}$. Once the preparation chamber was at high vacuum (pressure $<4 \times 10^{-4} \mathrm{~Pa}$ ), the cryostage temperature was raised to $-90^{\circ} \mathrm{C}$ for $30 \mathrm{~s}$ and then cooled again to $-130^{\circ} \mathrm{C}$. Subsequently, samples were sputter-coated with a 6-nm-thick platinum layer and immediately transferred to the SE M cryostage. Samples were examined at $-125^{\circ} \mathrm{C}$ with a M odel S-4700 field emission scanning electron microscope (H itachi, Tokyo, Japan) running either in the high-resolution mode, the normal mode, or the analytical mode, depending on the magnification used. SE M micrographs were recorded digitally at an acceleration voltage of 2-5 kV.

\section{Registration of Substrate Utilization Pattems in BIOLOG Microplates}

We used BIOLOG SF-N plates (Merlin Diagnostika $\mathrm{GmbH}$, Bornheim, Germany) that contained 95 different carbon sources in a microtiter plate format to determine the range of catabolic capabilities of the fungi tested. Inoculum was obtained by suspending conidia with a sterile spatula from fresh agar cultures in $5 \mathrm{ml} \mathrm{0.2 \%} \mathrm{carra-}$ geenan type II (Sigma, D eisenhofen, Germany); $100 \mu$ l of a conidial suspension adjusted to an $O D_{590}$ of 0.011 was used to inoculate each well. Incubation was at $21^{\circ} \mathrm{C}$ in the dark. Since the isolates exhibited differential growth rates on malt agar plates (data not shown) we decided not to 
TABLE 1

Characterization of Cladosporium I solates Recovered from Reeds at L ake Constance

\begin{tabular}{|c|c|c|c|c|c|c|c|}
\hline Strain & L ocation $^{1}$ & $\mathrm{H}$ abitat ${ }^{2}$ & Organ $^{3}$ & M orphology & ITS type ${ }^{4}$ & Actin accession & BIOLOG \\
\hline 4/97-48 & $M$ & $f$ & I & C. herbarum & $\mathrm{C}$ & AJ 300320 & See Table 4 \\
\hline $6 / 97-44$ & $M$ & $f$ & 1 & C. herbarum & $\mathrm{C}$ & As CBS 812.71* & n.d. \\
\hline $315 W$ & $M$ & $d$ & $r$ & C. herbarum & $\mathrm{C}$ & AJ300323 & See Table 4 \\
\hline $6 / 97-32$ & $\mathrm{R}$ & $d$ & $r$ & C. herbarum & $\mathrm{C}$ & As $5 / 97-9$ & See Table 4 \\
\hline $4 / 97-5$ & $M$ & $f$ & $r$ & C. herbarum & $\mathrm{C}$ & n.d. & n.d. \\
\hline $5 / 97-20$ & $M$ & $f$ & $r$ & C. herbarum & $\mathrm{C}$ & n.d. & n.d. \\
\hline $5 / 97-9$ & $M$ & $f$ & $r$ & C. herbarum & $\mathrm{C}$ & AJ 300315 & See Table 4 \\
\hline $6 / 97-3$ & $M$ & $f$ & $r$ & C. herbarum & $\mathrm{C}$ & n.d. & n.d. \\
\hline $4 / 97-19$ & $M$ & $f$ & $r$ & C. herbarum & n.d. & n.d. & n.d. \\
\hline $4 / 97-101$ & $\mathrm{R}$ & $f$ & $r$ & C. herbarum & C & n.d. & n.d. \\
\hline $4 / 97-41$ & $\mathrm{R}$ & $f$ & $r$ & C. herbarum & $\mathrm{C}$ & n.d. & n.d. \\
\hline 4/97-49 & $\mathrm{R}$ & $f$ & $r$ & C. herbarum & $\mathrm{C}$ & n.d. & n.d. \\
\hline 6/97-12 & $\mathrm{R}$ & $f$ & $r$ & C. herbarum & n.d. & n.d. & n.d. \\
\hline $4 / 97-6$ & $M$ & $f$ & s & C. herbarum & $\mathrm{C}$ & As 315W & See Table 4 \\
\hline $4 / 97-12$ & $M$ & $f$ & $\mathrm{~s}$ & C. herbarum & n.d. & n.d. & n.d. \\
\hline $6 / 97-4$ & $\mathrm{R}$ & $f$ & s & C. herbarum & C & As CBS $812.71 *$ & See Table 4 \\
\hline $6 / 97-56$ & $\mathrm{R}$ & $f$ & $\mathrm{~s}$ & C. herbarum & n.d. & n.d. & n.d. \\
\hline $6 / 97-48$ & $M$ & $f$ & I & C. oxysporum & $A$ & n.d. & n.d. \\
\hline $6 / 97-49$ & $M$ & $f$ & I & C. oxysporum & $A$ & n.d. & n.d. \\
\hline $4 / 97-17$ & $\mathrm{R}$ & $f$ & I & C. oxysporum & $A$ & AJ 300322 & See Table 4 \\
\hline $6 / 97-47$ & $\mathrm{R}$ & $f$ & I & C. oxysporum & $A$ & n.d. & n.d. \\
\hline $6 / 97-46$ & $M$ & $f$ & I & C. oxysporum & n.d. & n.d. & n.d. \\
\hline $6 / 97-68$ & $M$ & $d$ & $r$ & C. oxysporum & $A$ & AJ 300313 & See Table 4 \\
\hline $5 / 97-22$ & $M$ & $d$ & $r$ & C. oxysporum & $A$ & n.d. & n.d. \\
\hline $5 / 97-83$ & $M$ & $d$ & $r$ & C. oxysporum & $A$ & AJ 300316 & n.d. \\
\hline A14 & $\mathrm{R}$ & $d$ & $r$ & C. oxysporum & $A$ & As $4 / 97-17$ & See Table 4 \\
\hline RD 294 & $\mathrm{R}$ & $d$ & $r$ & C. oxysporum & $\mathrm{A}$ & AJ 300311 & See Table 4 \\
\hline 5/97-10 & $\mathrm{R}$ & $\mathrm{d}$ & $r$ & C. oxysporum & n.d. & n.d. & n.d. \\
\hline 4/97-11 & $\mathrm{R}$ & $f$ & $r$ & C. oxysporum & $A$ & n.d. & n.d. \\
\hline $4 / 97-3$ & $\mathrm{R}$ & $f$ & $r$ & C. oxysporum & $A$ & n.d. & n.d. \\
\hline $6 / 97-2$ & $\mathrm{R}$ & $f$ & $r$ & C. oxysporum & $A$ & As CBS 401.80* & See Table 4 \\
\hline $6 / 97-5$ & $\mathrm{R}$ & $f$ & $r$ & C. oxysporum & $A$ & As $4 / 97-17$ & See Table 4 \\
\hline $4 / 97-21$ & $\mathrm{R}$ & $f$ & $r$ & C. oxysporum & $\mathrm{A}$ & As $6 / 97-68$ & n.d. \\
\hline 4/97-42 & $\mathrm{R}$ & $f$ & $r$ & C. oxysporum & n.d. & n.d. & n.d. \\
\hline $5 / 97-21$ & $M$ & $\mathrm{f}$ & $r$ & C. oxysporum & B & n.d. & n.d. \\
\hline 5/97-17 & $M$ & $d$ & $s$ & C. oxysporum & $A$ & As $4 / 97-17$ & See Table 4 \\
\hline 6/97-34 & $M$ & $d$ & $\mathrm{~s}$ & C. oxysporum & $B$ & AJ 300314 & n.d. \\
\hline 5/97-111 & $\mathrm{R}$ & $f$ & s & C. oxysporum & $A$ & AJ 300318 & See Table 4 \\
\hline $4 / 97-20$ & $M$ & $f$ & $\mathrm{~s}$ & C. oxysporum & $\mathrm{B}$ & AJ 300321 & n.d. \\
\hline $5 / 97-8$ & $M$ & $f$ & $\mathrm{~s}$ & C. oxysporum & $B$ & AJ 300317 & n.d. \\
\hline $4 / 97-2$ & $\mathrm{R}$ & $f$ & s & C. oxysporum & $B$ & As $6 / 97-34$ & See Table 4 \\
\hline 5/97-11 & $\mathrm{R}$ & $f$ & $\mathrm{~s}$ & C. oxysporum & $\mathrm{B}$ & AJ 300319 & See Table 4 \\
\hline A13 & $\mathrm{R}$ & $f$ & $r$ & C. sp. & $\mathrm{D}$ & AJ 300312 & See Table 4 \\
\hline 4/97-4 & $\mathrm{R}$ & $f$ & $r$ & C. sp. & $\mathrm{D}$ & As A13 & See Table 4 \\
\hline
\end{tabular}

Note. Strains were sorted first by morphology and then by organ and site of isolation, respectively.

* See Table 2.

${ }^{1-3}$ D enotes the origin of the strains: ${ }^{1} \mathrm{R} / \mathrm{M}$, location: Reichenau/M ainau; ${ }^{2} \mathrm{f} / \mathrm{d}$, position in reed belt: flooded/dry; ${ }^{3} \mathrm{r} / \mathrm{s} / \mathrm{l}$, host organ: root/stem/leaf.

${ }^{4}$ ITS types A-D received EMBL Accession N os. AJ300332, AJ300337, AJ300333, and AJ300336, respectively. n.d., not determined.

score the results after a fixed incubation period, but at several time points as described before (Dobranic and Zak, 1999). For scoring, we recorded absorbances every other day by scanning plates on a M ikrotek Scanmaker 3 with the Adobe Photoshop 4.0 software. Files were saved in TIFF format and imported into the M ulti Analyst 1.0.2 software (Bio-Rad G mbH, M ünchen, Germany) to record average pixel densities. Results were transformed into a Microsoft Excel 98 datasheet to subtract water controls and to adjust negative values to zero. F or each time point 
TABLE 2

Reference Cultures U sed for Characterization of Cladosporium I solates from Reed

\begin{tabular}{lllr}
\hline \multicolumn{1}{c}{ Reference strain } & \multicolumn{1}{c}{ Host plant } & Location & ITS accession \\
\hline C. oxysporum CBS 125.80* & Cirsium vulgare & N etherlands & AJ 300332 \\
C. cladosporioides CBS 169.54* & Arundo sp. & Kew, E ngland & AJ300325 \\
C. cladosporioides CBS 401.80* & Triticum aestivum & N etherlands & AJ300335 \\
C. tenuissimum CBS 674.82* & Gossypium sp. & Jaffa, Israel & AJ300334 \\
C. herbarum CBS 812.71* & Polygonatum odoratum & Lisen, Czechoslovakia & AJ300331 \\
C. fulvum Dutch Race 4† & Lycopersicon esculentum & N etherlands & AJ300333 \\
Septoria tritici L951\# & Triticum aestivum & E ngland & LJ 300325430 \\
\hline
\end{tabular}

* I solation details as on CBS listings.

$\uparrow$ Curtis et al. (1994).

\#Received from D. B. Collinge (D epartment of Plant Biology, KVL, F rederiksberg, D enmark).

we formed the sum of the 95 corrected pixel densities to create kinetics. F or the following calculations, we used the data sets corresponding to the beginning of the respective plateaus. We defined four classes for growth, i.e., 0-1$2-3$, to better differentiate between any two strains growing either vigorously or poorly on a particular carbon source. In such a case a 0-1 matrix would record both results as " 1 " but the extended matrix would note a " 1 " versus a "3." We defined the four classes from $0-15$, $15-30,30-60$, and $60-100 \%$, respectively; $100 \%$ indicates maximum density obtained with any carbon source (mostly glucose) on a given microtiter plate. The resulting data set was exported to the software package PAU P 4.0d64 (Swofford, 2000). M aximum-parsimony analysis used a matrix that weighted the growth differences according to the four classes explained above and the Wagner method implemented in PAUP 4.0d64 with equal weighting. Using stepwise addition of sequences, heuristic searches with 1000 bootstrap replicates were performed using tree bisection-reconnection (TBR). Branches with more than $50 \%$ support were used further in unrooted phylograms.

\section{DNA Extraction, PCR, and Sequence Reactions}

For the preparation of fungal genomic DNA, mycelial material was removed from agar plates with a sterile scalpel, transferred to an E ppendorf tube, and flash-frozen in liquid nitrogen. During thawing, micropestles (Biozym Diagnostik GmbH, Hessisch Oldendorf, Germany) were used to improve lysis. After adding $500 \mu \mathrm{l}$ of a $10 \%$ suspension of Chelex 100 cation exchange resin (Bio-Rad $\mathrm{GmbH}$ ) in sterile water and mixing for $5 \mathrm{~s}$, incubation for $1 \mathrm{~h}$ at $65^{\circ} \mathrm{C}$ followed. The suspension was then mixed for $5 \mathrm{~S}$ and incubated for $5 \mathrm{~min}$ at $95^{\circ} \mathrm{C}$. The supernatant resulting from a centrifugation for $5 \mathrm{~min}$ at $14,000 \mathrm{rpm}$ was transferred to a fresh tube and kept at $-20^{\circ} \mathrm{C}$.

Plant genomic DNA was isolated from tissue samples stored at $-70^{\circ} \mathrm{C}$. Several cleaned parts of the same organ from one individual plant were pooled and homogenized with mortar and pestle in the presence of liquid nitrogen, resulting in about $5 \mathrm{ml}$ of powdered material. About 100 mg powder was processed with the NucleoSpin Plant genomic D N A kit (M acherey-N agel G mbH , D üren, Germany) following the instructions provided. DNA quality was controlled by agarose gel electrophoresis.

PCRs were carried out in a MJ Research PTC 100 thermocycler (Biozym Diagnostik $\mathrm{GmbH}$ ) to generate template DNA for sequencing. F ungal ITS regions were amplified with ITS1F as forward and ITS4 as reverse primer (White et al., 1990; Gardes and Bruns, 1993). Reaction mixtures contained $0.5 \mu \mathrm{l}$ fungal D N A solution in $50 \mu$ l of reaction mix ( $1 \times$ PCR buffer (M BI F ermentas $\mathrm{G} \mathrm{mbH}$, St. Leon-Roth, Germany), $1.5 \mathrm{mM} \mathrm{M} \mathrm{gCl}{ }_{2}, 0.2 \mathrm{mM}$ dNTPs, $0.5 \mathrm{mg} / \mathrm{ml}$ bovine serum albumin, $0.3 \mu \mathrm{M}$ each primer, and $0.04 \mathrm{U} / \mu \mathrm{l}$ of recombinant Taq Polymerase (M BI Fermentas)). An initial denaturation step of $94^{\circ} \mathrm{C}$ for $150 \mathrm{~s}$ was followed by 15 cycles of a touch-down PCR protocol: $94^{\circ} \mathrm{C}$ for $30 \mathrm{~s}, 70^{\circ} \mathrm{C}$ for $30 \mathrm{~s}$ with a decrease of $1^{\circ} \mathrm{C}$ per cycle, and $72^{\circ} \mathrm{C}$ for $30 \mathrm{~s}$. This was immediately succeeded by 30 cycles of the following protocol: $94^{\circ} \mathrm{C}$ for $30 \mathrm{~s}, 55^{\circ} \mathrm{C}$ for $30 \mathrm{~s}$, and $72^{\circ} \mathrm{C}$ for $30 \mathrm{~s}$ plus one additional second per cycle. After a final extension at $72^{\circ} \mathrm{C}$ for $10 \mathrm{~min}$, reactions were cooled to $2^{\circ} \mathrm{C}$. F ungal actin gene fragments were amplified using primers $F$ ungAct. $F$ and $F$ ungAct. $R 1$ (Table 3) that were designed during this study based on fungal reference sequences currently available in public sequence databases. PCR conditions were as for ITS fragments with the exception that the primer concentration was set at $1 \mu \mathrm{M}$ and the final annealing temperature was 
TABLE 3

Primers D esigned during This Study

\begin{tabular}{|c|c|c|c|c|}
\hline Primer & Orientation & Target sequence & Target organisms & Sequence $\left(5^{\prime}\right.$ to $\left.3^{\prime}\right)$ \\
\hline Pa-ITS.F 1 & Forward & ITS1 & P. australis & CGGGAGGGGAGGGGACGAAACAGAA \\
\hline Pa-ITS.R1 & Reverse & ITS2 & P. australis & GGTACGCCGGCAGCCCCAACTTC \\
\hline FungAct.F 1 & Forward & Actin & Fungi & TGGCAYCAYACITTYTAYAAYGA \\
\hline FungAct.R 1 & Reverse & Actin & Fungi & CCICCIATCCAIACIGARTAYTT \\
\hline CladAct.F 1 & Forward & Actin & Cladosporium spp. & CGTYCGYGACATCAAGGAG \\
\hline CladAct.R 1 & Reverse & Actin & Cladosporium spp. & CTGGCTSGCGGTYTGGAT \\
\hline CladAct.F 3 & Forward & Actin & Cladosporium spp. & GCCGTGACTTGACCGACTAC \\
\hline CladAct.R3 & Reverse & Actin & Cladosporium spp. & CCGGGGTACATGGTGGTAC \\
\hline A14Act.R 1 & Reverse & Actin & C. oxysporum (A14) & TGCAGAAATGAGAAGGAAGTGAAC \\
\hline 4/97-2Act.R 1 & Reverse & Actin & C. oxysporum (4/97-2) & GACTGTGCGGTTTGTTAGCATCTT \\
\hline 315WAct.R 1 & Reverse & Actin & C. herbarum (315W) & GTGTGGGATTTCAAAGTCGGA \\
\hline A13Act.R 1 & Reverse & Actin & C sp. (A13) & AGACTGTGTCATGTTAGCAACTTGAG \\
\hline
\end{tabular}

$50^{\circ} \mathrm{C}$ after 15 cycles of the touch-down block. PCR fragments were purified with the QIAquick PCR Purification $\mathrm{K}$ it (Qiagen $\mathrm{GmbH}, \mathrm{H}$ ilden, G ermany).

We designed PCR primers (Pa-ITS.F 1 and Pa-ITS.R 1; see Table 3) directed against the published ITS sequence of $P$. australis (Accession N O. AF 019810) to control for general amplificability of plant DNA preparations. Assays contained $0.5 \mu \mathrm{l}$ of plant DNA in a volume of $19.5 \mu \mathrm{l}$ of reaction mix (same as above). Cycle conditions were as for fungal ITS fragments (see above) with the exception that the final annealing temperature was set at $58^{\circ} \mathrm{C}$ after 10 cycles of a touch-down block.

$P C R$ fragments were subjected to sequencing reactions using the $A B I$ Prism BigD ye Terminator Cycle Sequencing Kit (PE Applied Biosystems, Weiterstadt, Germany) according to the provided instructions. For ITS fragments primers were ITS1F, ITS2, ITS3, and ITS4 (White et al., 1990; $G$ ardes and Bruns, 1993). F or actin gene fragments primers were $F$ ungAct.F 1 , F ungAct.R 1 , CladAct.F 1 , and CladAct.R 1 (Table 3). The latter two were designed during this study to match actin sequences from all isolates of the genus Cladosporium. DNA sequences were determined on an ABI377 automated sequencing system (PE Applied Biosystems). DNA sequences were assembled using the program SeqM an from the D NASTAR software package (GATC GmbH, Konstanz, Germany).

Sequences obtained during this work have been submitted to the EMBL database and have been assigned the Accession N os. AJ 300310 to AJ 300337.

\section{Phylogenetic Analysis}

Pairwise alignments of sequences were carried out with the $M$ artinez/N eedleman-Wunsch algorithm implemented in the DNASTAR module M egAlign. M ultiple alignments were created with the Clustal algorithm, which is implemented in the same module, and were manually improved and exported to the software package PAUP 4.0d64 (Swofford, 2000). The taxa were added by stepwise addition and analyzed using maximum-parsimony with equal weighting of the nucleotides. Gaps were treated as missing characters. The confidence of phylogenetic trees was estimated with 1000 heuristic bootstrap replicates using the tree bisectionreconnection (TBR) branch-swapping algorithm. B ootstrap values below $50 \%$ were collapsed. ITS and actin datasets were rooted using $\mathrm{S}$. tritici as outgroup. Alignments of ITS and actin trees were deposited at the TreeBase database (http://www.herbaria.harvard.edu/treebase/).

Concordance of the ITS and actin datasets was analyzed with the partition homogeneity test included in PAUP $4.0 \mathrm{~d} 64$ by using 1000 repartitions with M AXTRE ES set to 1000.

To compare alternative topologies the $\mathrm{K}$ ishino- $\mathrm{H}$ asegawa likelihood test implemented in PAUP 4.0.d64 was used. Standard deviation from the original most parsimonious tree and $\mathrm{P}^{*}$, where $\mathrm{P*}$ shows whether a tree is significantly worse than the most parsimonious tree, were used to test whether hypothetical topologies could be rejected with confidence.

\section{Nested PCR Assay}

We developed a nested PCR assay based on the actin gene sequences established during this work to detect and differentiate distinct types of Cladosporium in reed D NA. The first amplification step relied on primers CladAct.F 3 and CladAct.R3 (Table 3) that were designed to match actin sequences from all Cladosporia. PCR conditions 

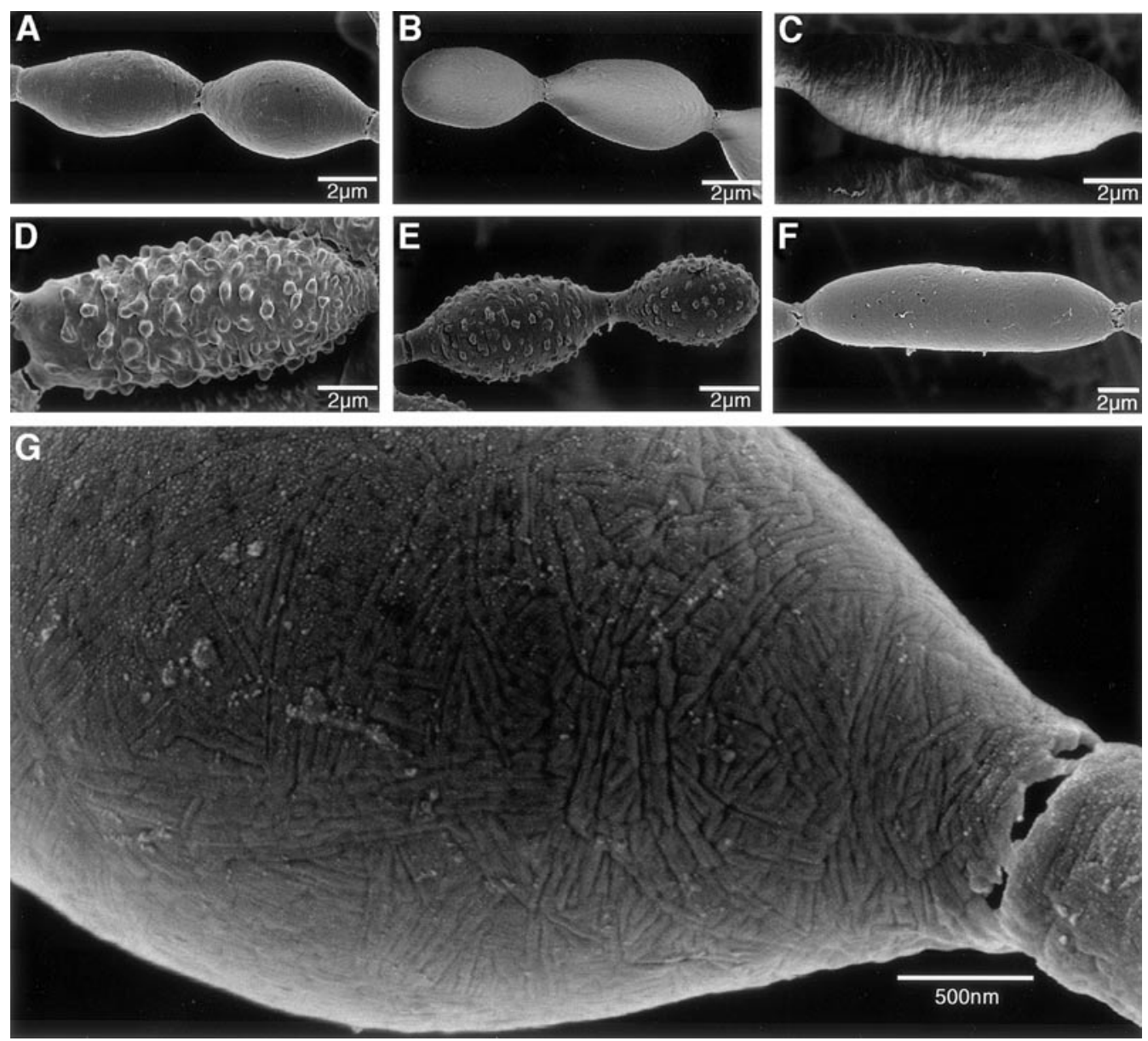

FIG. 1. LTSEM of native conidia from reference cultures. (A) Cladosporium oxysporum CBS 125.80; (B) C. tenuissimum CBS 674.82 ; (C) C. cladosporioides CBS 401.80; (D) C. herbarum CBS 812.71; (E) C. cladosporioides CBS 169.54; (F) C. fulvum Dutch Race 4; (G) C. oxysporum CBS 125.80 (higher magnification than that of A). For details of isolates, see Table 2.

were generally as above except that the annealing temperature was set to $62^{\circ} \mathrm{C}$ after 10 cycles of a touch-down block with a decrease of $1^{\circ} \mathrm{C}$ per cycle. The second PCR made use of variable intron sequences discovered in Cladosporium actin genes to differentiate between products from the first step. In all cases, the forward primer was CladAct.F 1, which matched all Cladosporia, whereas four different reverse primers were placed within the introns to match only the particular strains from which it was derived (Table 3). Reaction mixtures were generally as described above with the exception that $1 \mu \mathrm{l}$ of a 10 -fold dilution of the first PCR step was used as template in a total volume of $20 \mu \mathrm{l}$. Cycling parameters were as above but annealing and synthesis steps were shortened to $15 \mathrm{~s}$. Annealing temperatures were optimized for each primer combination and were $65^{\circ} \mathrm{C}$ for CladAct.F 1 with A14Act.R $1,66^{\circ} \mathrm{C}$ for CladAct.F 1 with 4/97-2Act.R 1 and for CladAct.F 1 with 315WAct.R 1 , and $59^{\circ} \mathrm{C}$ for CladAct.F 1 with A13Act.R 1 . Sets of appropriate positive and negative controls were included by using pure genomic DNA from appropriate strains of Cladosporium sp.

\section{RESULTS}

\section{Morphological Characterization}

To characterize the isolates from reed we first studied reference cultures (obtained from CBS) for the definition of typical characters recognizable by LTSEM in their native state. C. oxysporum CBS 125.80 (Fig. 1A), C. 
tenuissimum CBS 674.82 ( $\mathrm{F}$ ig. 1B), and C. cladosporioides CBS 401.80 (F ig. 1C) had smooth surfaces at lower magnifications. At higher magnification, $C$. oxysporum CBS 125.80 (Fig. 1G) and the other two smooth reference cultures exhibited a layer of rodlet fascicles on the whole conidial surface including the connections. Such structures corresponded to agglomerated hydrophobins (Wosten and de Vocht, 2000). Conidia of these strains showed considerable variation in branching patterns, size, and shape (not shown). These characters were therefore of limited value and not used for further differentiation. $C$. herbarum CBS 812.71 (F ig. 1D) exhibited digitate ornamentation, with rounded projections on the surface. $C$. cladosporioides CBS 169.54 (Fig. 1E) showed granulate ornamentations with rounded discrete projections. The different appearances of C. cladosporioides CBS 169.54 and CBS 401.80 observed by LTSEM provided first hints for problematic assignments of reference cultures.

When analyzing the isolates from reed by L TSE $M$ three distinct types of conidia were found. Conidia of the first type, represented by isolates A14 (Fig. 2A) and 4/97-2 ( $F$ ig. 2B), were smooth, exhibiting rodlets at high magnifications identical to those of $C$. oxysporum CBS 125.80, C. tenuissimum CBS 674.82, and C. cladosporioides CBS 401.80. Other characters (conidium size, branching patterns, etc.) were highly variable. The second type, represented by isolate $315 \mathrm{~W}$ (Fig. $2 \mathrm{C}$ ), exhibited surface ornamentations identical to those of $C$. herbarum CBS 812.71. The third type, represented by isolate $A 13$ (Fig. 2D), showed at higher magnifications irregular aculeate projections that were found neither in any of the reference cultures studied here nor in others (D avid, 1997). The ambiguities seen with some reference cultures prompted further molecular studies aimed to better characterize the isolates from reed.

\section{Genetic Diversity of Cladosporium Sp. from Reed}

Pairwise comparisons of all sequences from our reed isolates revealed four different ITS sequence types, designated A-D (see Table 1). Overall, the sequences were quite similar, $94.2 \%$ being the lowest score with ITS type $D$ versus type $A$ or type $B$. Types $A$ and $B$ exhibited only one varying nucleotide separating the morphotype characterized as C. oxysporum (see Figs. $2 A$ and $2 B$ ) into two subgroups. Type A was identical to both the ITS sequences from $C$. oxysporum CBS 125.80 and C. cladosporioides CBS 401.80. C. tenuissimum CBS 674.82 had only one exchanged nucleotide compared to ITS type A.
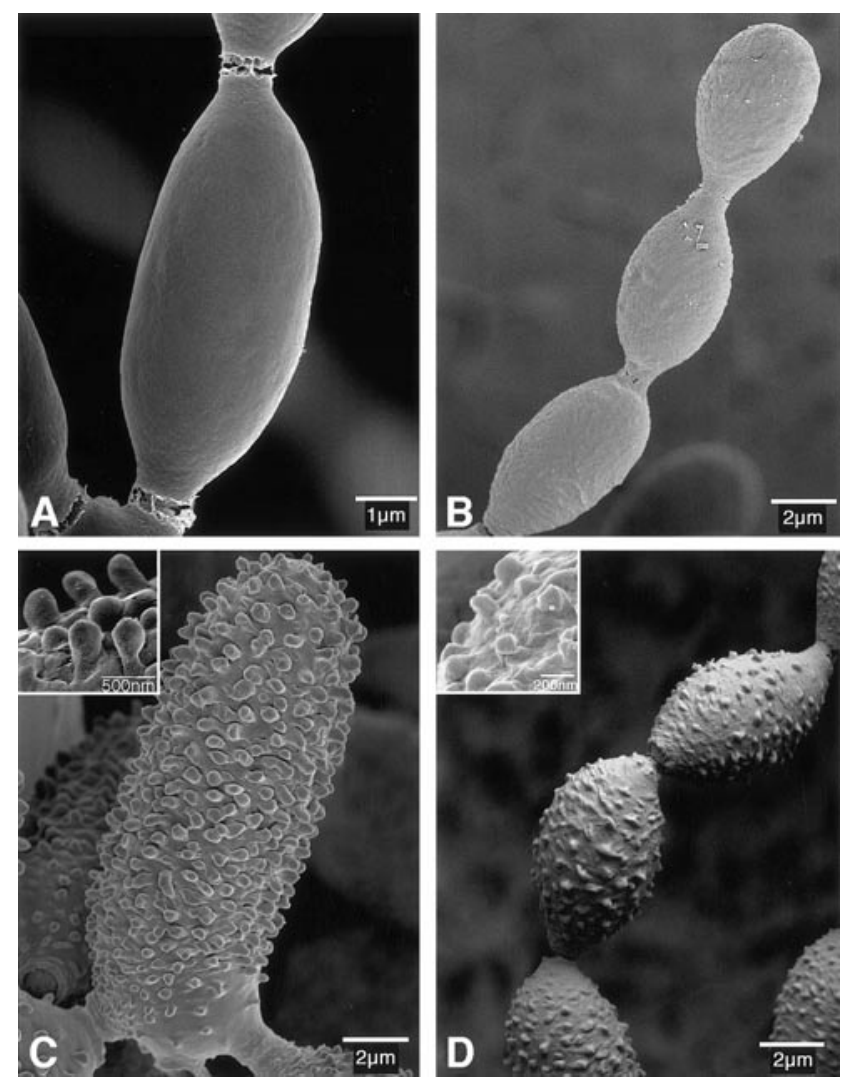

FIG. 2. LTSEM of native conidia from Cladosporium isolates recovered from Phragmites australis. (A) isolate A14; (B) isolate 4/97-2; (C) isolate $315 \mathrm{~W}$; (D) isolate A13. F or details of isolates, see Table 1.

Type B did not find a perfect match. The correlation of ITS type $C$ with the $C$. herbarum morphotype was further validated by its identity to the ITS sequence from $C$. herbarum CBS 812.71. ITS type D corresponding to the Cladosporium sp. represented by isolate $A 13$ matched neither any of our reference sequences nor those currently deposited in public databases. The second reference culture included in this study for C. cladosporioides (CBS 169.54) was different from $C$. cladosporioides CBS 401.80 by five nucleotides and did not match any sequence of the reed-associated Cladosporia.

To embed our new sequences within a broader phylogenetic context established in the literature, we assembled a phylogenetic tree comprising all ITS sequences for Cladosporium currently deposited in public databases, one sequence for ITS types $A$ to $D$ and all seven reference cultures sequenced in this study (Fig. 3). All entries displayed belong to plant-associated Cladosporia since medically relevant Cladosporia were recently shown to be only distantly related to the former ( $M$ asclaux et al., 1995). One 


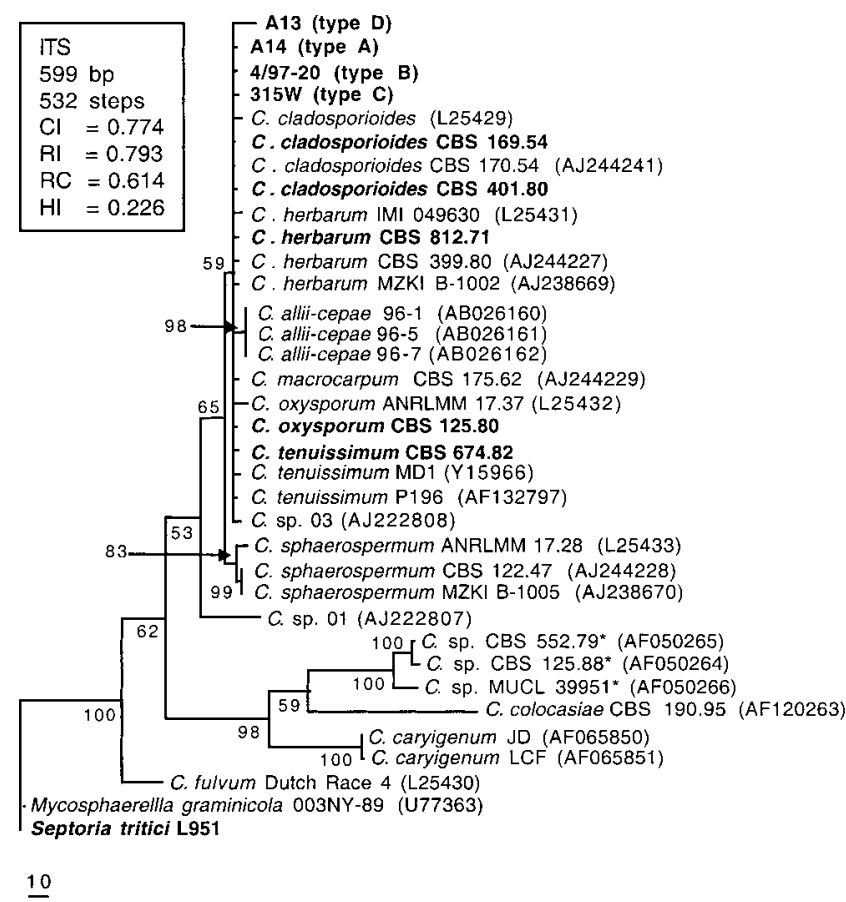

FIG. 3. Phylogram displaying the relationships between four different types (A-D) of ITS1-5.8S-ITS2 rD N A sequences from Cladosporium spp. isolated from reed and reference cultures. Sequences established during this study are in boldface. References, which were taken from E M BL and GenBank databases, are in plain type. Accession numbers are indicated in parentheses. The tree was generated by maximum-parsimony using 1000 bootstrap replicates in the program PAUP 4.0.d64. *CBS 552.79, CBS 125.88, and MUCL 39951 were reassigned as Capronia spp. (Untereiner and Naveau, 1999).

large unresolved clade (59\% bootstrap support) comprised strains assigned to $C$. cladosporioides, C. oxysporum, C. tenuissimum, $C$. herbarum, and $C$. macrocarpum. Bootstrap-supported branches lead to $C$. allii-cepae (leaf blotch on onion and leek), C. sphaerospermum, Cladosporium spp. accessions AF 050264-AF 050266 (isolates from wood, reassigned as Capronia spp. (Untereiner and $\mathrm{Na}$ veau, 1999)), and C. caryigenum (scab on pecan).

To derive a more detailed molecular phylogeny for species within the unresolved part of the tree we also determined partial actin sequences for a subset of 23 isolates from reed and the seven reference cultures. The PCR primers F ungAct.F 1 and F ungAct.R 1 (see Table 3) were directed against conserved regions of currently known fungal actin genes to amplify fragments from codon 84 to codon 342 . We detected an intron inserted at exactly the same position (after codon 299) in the actin PCR fragments from all Cladosporia analyzed, but also in the related $\mathrm{S}$. tritici. The sequence of this intron was highly variable. After excising the introns and translating to peptide sequences, BLASTP searches revealed that the closest matches in current databases are the actins from B otrytis cinerea, Acremonium chrysogenum, and Aspergillus nidulans. These genes also have an intron at the very same position (data not shown). With the exception of $C$. fulvum and $\mathrm{S}$. tritici, all peptide sequences determined in this study were identical since nucleotide variations generally corresponded to silent changes. The same subset of 30 strains was utilized to generate a phylogeny for the actin gene and, for comparison, for the ITS region. The lower diversity of the sequences used to generate this second ITS tree (F ig. 4A) - when compared to that shown in Fig. 3- generally increased the bootstrap support above 50\%, now separating ITS types A-D (Fig. 4A). C. oxysporum CBS 125.80, C. tenuissimum CBS 674.82, and C. cladosporioides CBS 401.80 clustered with ITS type $A$ and $C$. herbarum CBS 812.71 with ITS type $C$, whereas I TS types $B$ and $D$ and $C$. cladosporioides CBS 169.54 remained on separate branches. The corresponding actin tree ( $F$ ig. 4B) mirrored the separation of the ITS types A-D seen in F ig. $4 A$, but exhibited higher resolution leading to further differentiation in terminal branches. Here, ITS type B formed two sister clades but bootstrap support for the monophyly of type B was below $50 \%$ (data not shown).

The topologies of ITS and actin trees were confirmed to be highly concordant $(P=0.99)$ by a partition homogeneity test. Therefore, both datasets were combined and analyzed using the total evidence (Fig. $4 \mathrm{C}$ ). The branching pattern of the combined tree was highly similar to that seen in the actin tree with the exception of branches comprising C. cladosporioides CBS 169.54 and C. tenuissimum CBS 674.82.

\section{Physiological Diversity of Cladosporium Sp. from Reed}

The above analysis revealed four putative species of Cladosporium that were all recovered from the same host species. F urthermore, we discovered a high genetic diversity at the population-species interface. This raised the question whether there were physiological differences at the species or infraspecific levels that might indicate specialization for the location or host habitat or host organ from where these isolates were initially retrieved. Therefore, we analyzed the substrate utilization patterns of 18 isolates from reed (see Table 1) on 95 different carbon sources implemented in BIOL OG SF -N microtiter plates. The resulting growth patterns (Table 4 ) were used to create a phylogenetic tree by parsimony analysis ( $\mathrm{Fig}$. 5). 
A

\begin{tabular}{|l|}
\hline ITS \\
540 bp \\
109 steps \\
$\mathrm{Cl}=0.963$ \\
$\mathrm{RI}=0.968$ \\
$\mathrm{RC}=0.932$ \\
$\mathrm{HI}=0.037$ \\
\hline
\end{tabular}

B

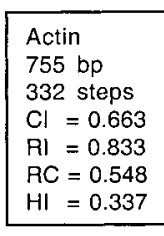

A $\quad \begin{aligned} & \mathrm{RC}=0.548 \\ & \mathrm{HI}=0.337\end{aligned}$

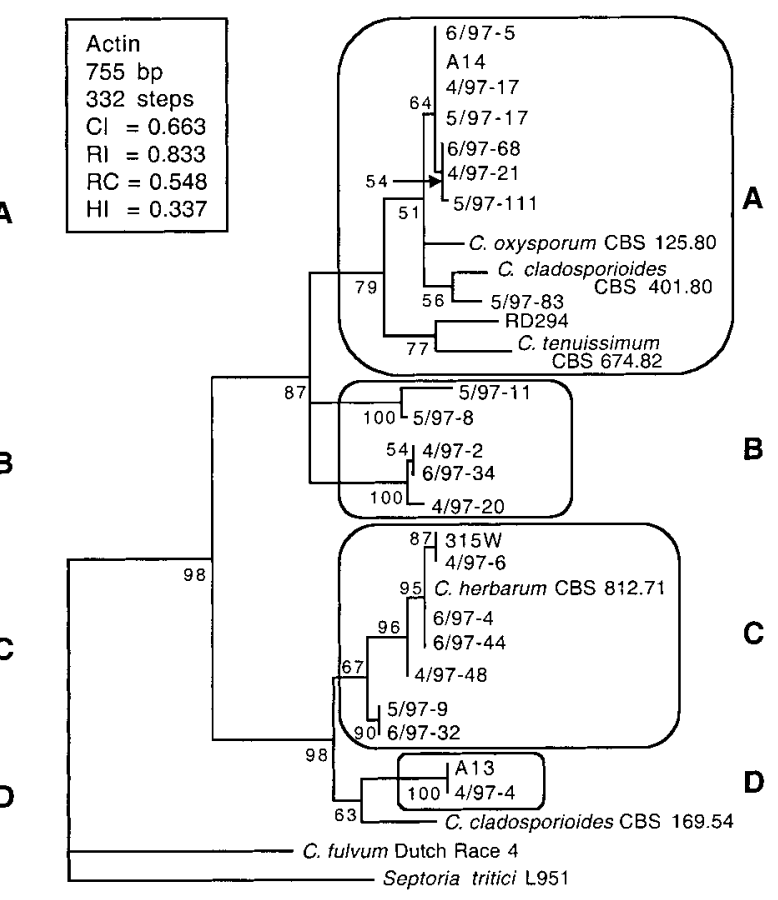

B

B
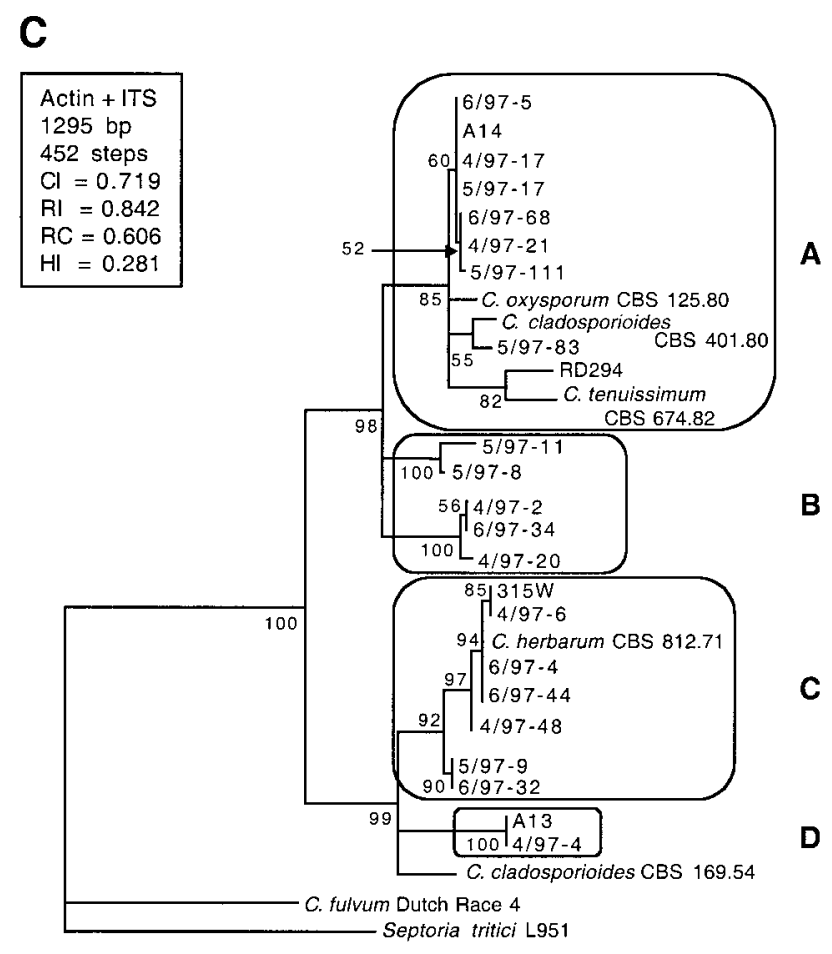

10

FIG. 4. Phylogram displaying the relationships between 23 Cladosporia from reed and seven additional reference cultures. (A) ITS-tree; (B) actin tree; (C) combined ITS-actin tree. The trees were generated by maximum-parsimony using 1000 bootstrap replicates with the program PAUP 4.0.d64. (A) ITS types A, C, and D form separate monophyletic clades with bootstrap values above 50\%. ITS type B forms an unresolved cluster adjacent to type A. (B) and (C) show similar topologies with better bootstrap support for the monophyly of the types A, C, and D. In addition type B forms two sister clades to type A. 
TABLE 4

Carbon Catabolite Spectra of Reed-Associated Cladosporia on BIOLOG SF-N M icrotiter Plates

I solate

Carbon sources 1 to 96 integrated in BIOLOG plates ${ }^{a}$

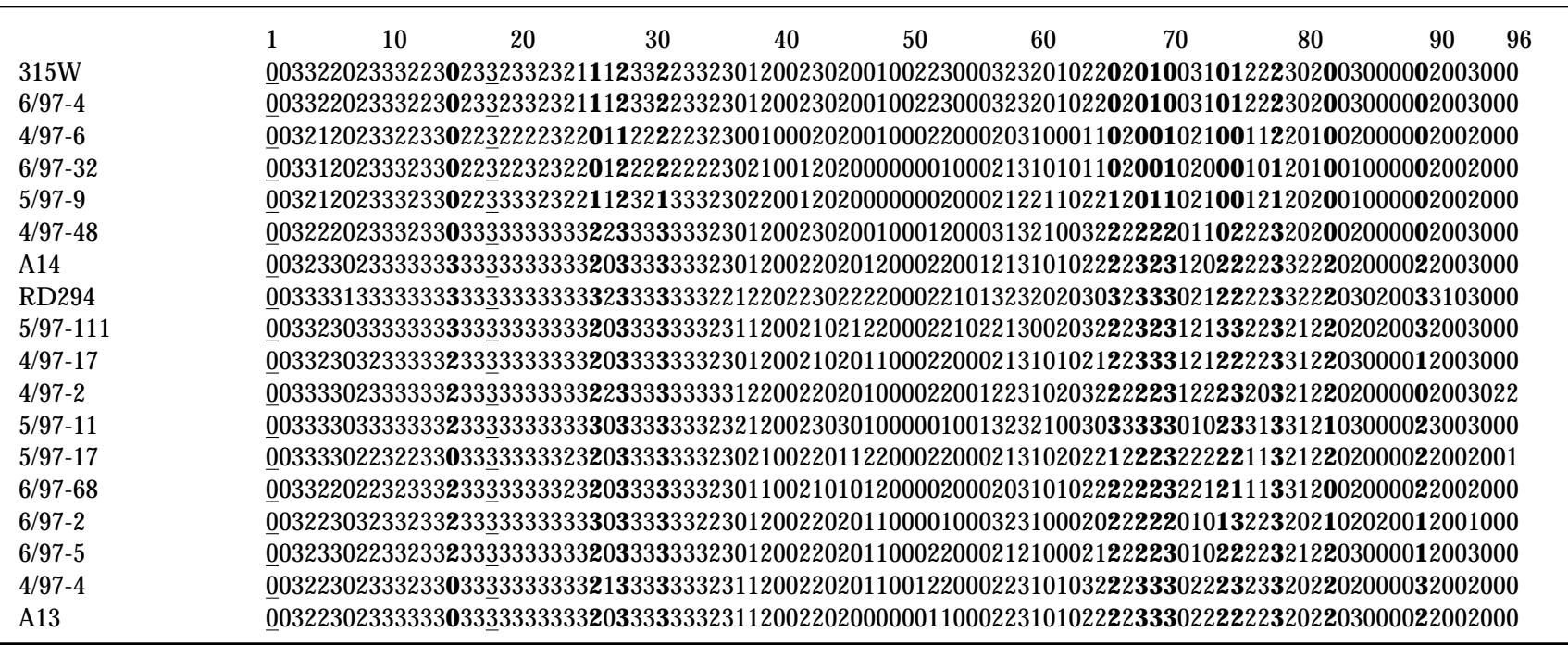

Note. I solates were sorted according to the order obtained in the phylogeny shown in Fig. 5 .

${ }^{a}$ G rowth patterns were scored from 0 (no growth) to 3 (maximal growth) as detailed under $\mathrm{M}$ aterials and $\mathrm{M}$ ethods and recorded in numerical order from carbon source 1 to 96 . For reference, negative (no carbon source, well 1) and positive controls (glucose, well 18) are underlined. Carbon sources that differentiated the major groups are indicated by boldface. These were from left to right: I -fucose, beta-methyl-d-glucoside, $d$-raffinose, sucrose, I -Ala, I -Asn, I -Asp, I -Glu, hydroxy-I -Pro, I -L eu, I -Pro, I -Thr, and phenylethylamine.

Analyses with the Wagner method with equal weights gave identical results (data not shown). Strains with ITS type C (C. herbarum) formed a monophyletic clade, whereas strains belonging to ITS types $A$ and $B$ (C. oxysporum) remained unseparated. The two isolates for ITS group $D$ (A13 and 4/97-4) that were distinguished by morphology and molecular analysis from the other groups were also differentiated by the BIOLOG analysis. Groupings at the terminal branches did not indicate correlation with location, habitat, or organ where the fungi were originally isolated. In addition, the topology of the $\mathrm{C}$. herbarum clade seen in the BIOLOG tree was not identical to that seen in the actin tree (see Fig. 4B). M ost of the differences underlying the tree shown in Fig. 5 are caused by poorer growth of $C$. herbarum on certain carbon sources compared with other groups. This was the case with several amino acids including I -Ala, I -Asn, I -Asp, I -Glu, I -L eu, I -Pro, and I -Thr, but also with I -fucose, d-raffinose, and sucrose (see Table 4).

\section{Nested PCR Assay for Differentiation of Cladosporium Sp. in Reed DNA}

The highly variable intron sequence discovered in the actin genes from Cladosporium spp. allowed the develop- ment of a nested PCR strategy for tracking closely related fungi in DNA preparations isolated from $P$. australis. Reactions with fungal genomic D N A were used to control the specificity of the conditions for PCRs with reed DNA as template. Figure $6 \mathrm{~A}$ shows that all templates yielded bands (440 bp) after the first PCR step with primers targeting sequences conserved within the actin genes from all Cladosporia analyzed. We were able to differentiate between the four targets by using nested primers in the second PCR step that took advantage of the divergent sequences in the intron. As shown in Fig. $6 \mathrm{~A}$ only $\mathrm{DNA}$ of the targeted strain produced the respective band (310$330 \mathrm{bp}$ ) but not DNA of the three other strains.

We used total DNA isolated from roots, stems, and leaves of eight reed plants harvested in August and from roots and shoots of eight plants harvested in April to compare the distribution of the different Cladosporia on reed at peak biomass and at the beginning of the growing season, respectively. All DNA preparations were initially controlled for general amplificability by a PCR assay directed against the ITS region of $P$. australis ( $F$ igs. $6 B$ and $6 C)$ and then used for the four nested PCRs. This approach allowed patterns of cocolonization to be deduced, i.e., how many different Cladosporia were present on the 


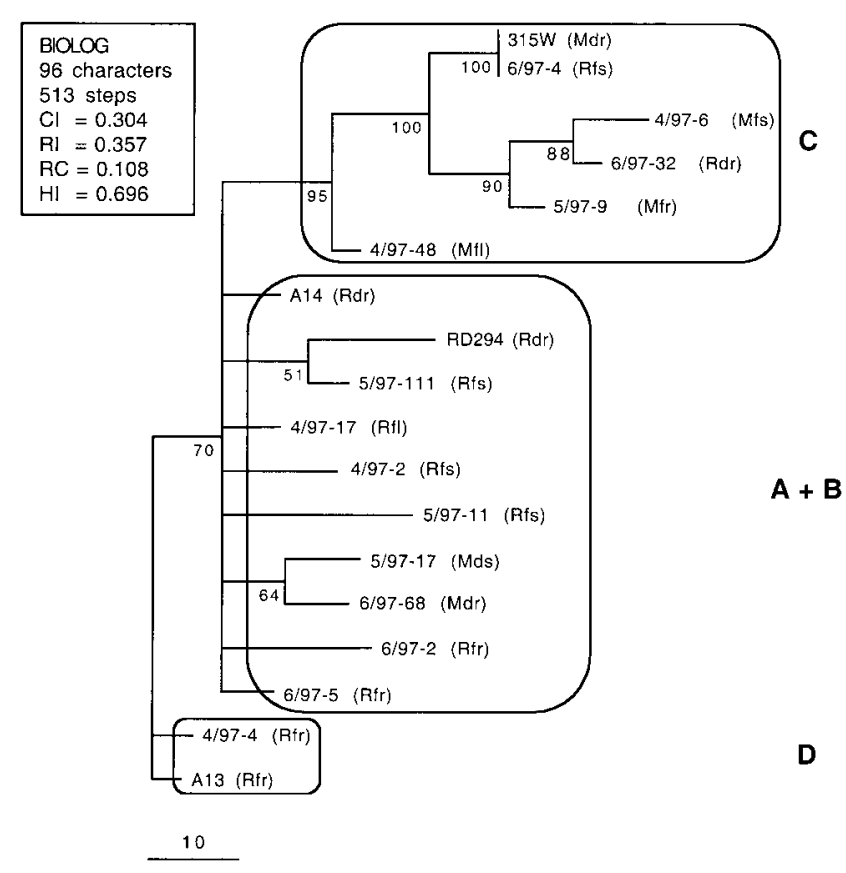

FIG. 5. Phylogram displaying the relationships between 18 Cladosporia from reed as derived from carbon utilization patterns of BIOLOG microtiter plates. L etters in parentheses designate the sampling histories of the respective strains as shown in Table 1 , i.e., $R / M$, location: Reichenau/M ainau; $f / d$, position in reed belt: flooded/dry; $r / s / l$, host organ: root/stem/leaf. The tree was generated by maximum-parsimony using a matrix that weighted the growth differences according to four classes (see Table 4). Only branches with bootstrap values above $50 \%$ are presented.

respective organs of each reed plant. In 10 of the 24 August samples we could not detect any of the Cladosporia under investigation, whereas 6 samples had just one detectable type (Fig. 6C). In 4 samples we observed two different fungi and in 2 samples three and four different fungi, respectively. There was no apparent exclusion of any group by any other. In April samples these fungi were much rarer than in August samples with the exception of Cladosporium sp. type A13 which might have the ability to colonize the host earlier than others.

\section{DISCUSSION}

Species belonging to the genus Cladosporium are ascribed a variety of life styles ranging from saprotrophic, through epiphytic or endophytic, to pathogenic or even mycoparasitic (Ellis, 1971; David, 1997; Moricca et al.,
1999). We have recovered a collection of Cladosporia from common reed that could theoretically fall into any of these types. The sampling covered two locations at Lake Constance with two habitat types each, one being permanent and the other just rarely flooded. F urthermore, sampling differentiated between host organ, i.e., leaf, stem, and root. I solates falling into the genus Cladosporium appeared to be generally recoverable from all organs and all sites. Here, we first differentiate these Cladosporium isolates by DNA sequence analysis and conidium surface ultrastructure as visualized by LTSEM and then address the ecology of these fungi.

Cladosporium is an anamorph genus. Classically, species within the genus were defined based on the morphological species concept but examination of the literature indicated repeated problems with assignments (D e Vries, 1967; Ellis, 1971, 1976; D ugan and Roberts, 1994; D avid, 1997; H arrington et al., 2000). In an earlier, smaller-scaled study, ITS data were used to establish a molecular phylogeny (Curtis et al., 1994). Here, we combine both approaches to advance the current taxonomy of Cladosporium.

LTSE M revealed three distinct kinds of conidia among the reed-associated Cladosporium isolates. O ne was identified as $\mathrm{C}$. oxysporum, one was typical for $\mathrm{C}$. herbarum, and for the last we did not find a matching reference. The first showed smooth conidial surfaces; the other two showed distinctly ornamented surfaces. To investigate the development of the latter we observed younger stages (not shown) in addition to those differentiated conidia depicted here. Young conidia were initially smooth and the extrusions appeared to eventually break from the inside through the hydrophobin layer. We did not observe the rodlet layer on mature extrusions under the conditions employed.

A phylogeny constructed from all currently available ITS sequences did not allow unambiguous linkage of our strains to established species, probably because of too little sequence variation within certain groupings of plant-associated Cladosporia. We found $C$. fulvum basal to the other species of that genus. M ost Septoria are now being placed in Stagonospora, which forms a monophyletic genus in the Leptosphaeriaceae (C unfer and U eng, 1999). In contrast, M. graminicola (anamorph: S. tritici) appeared to be only distantly related to Stagonospora, which questioned the grouping of $\mathrm{C}$. fulvum and $\mathrm{M}$. graminicola to their respective genera (C unfer and Ueng, 1999).

A second ITS phylogeny created from a subset of sequences originating from 23 reed isolates and seven reference cultures resolved the same three clusters seen with LTSEM but additionally separated one of those- the $C$. 
A

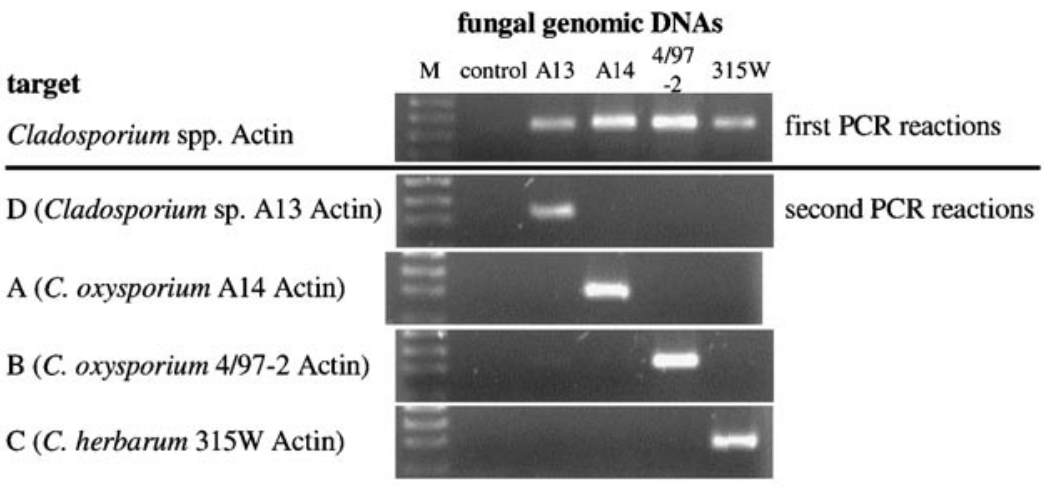
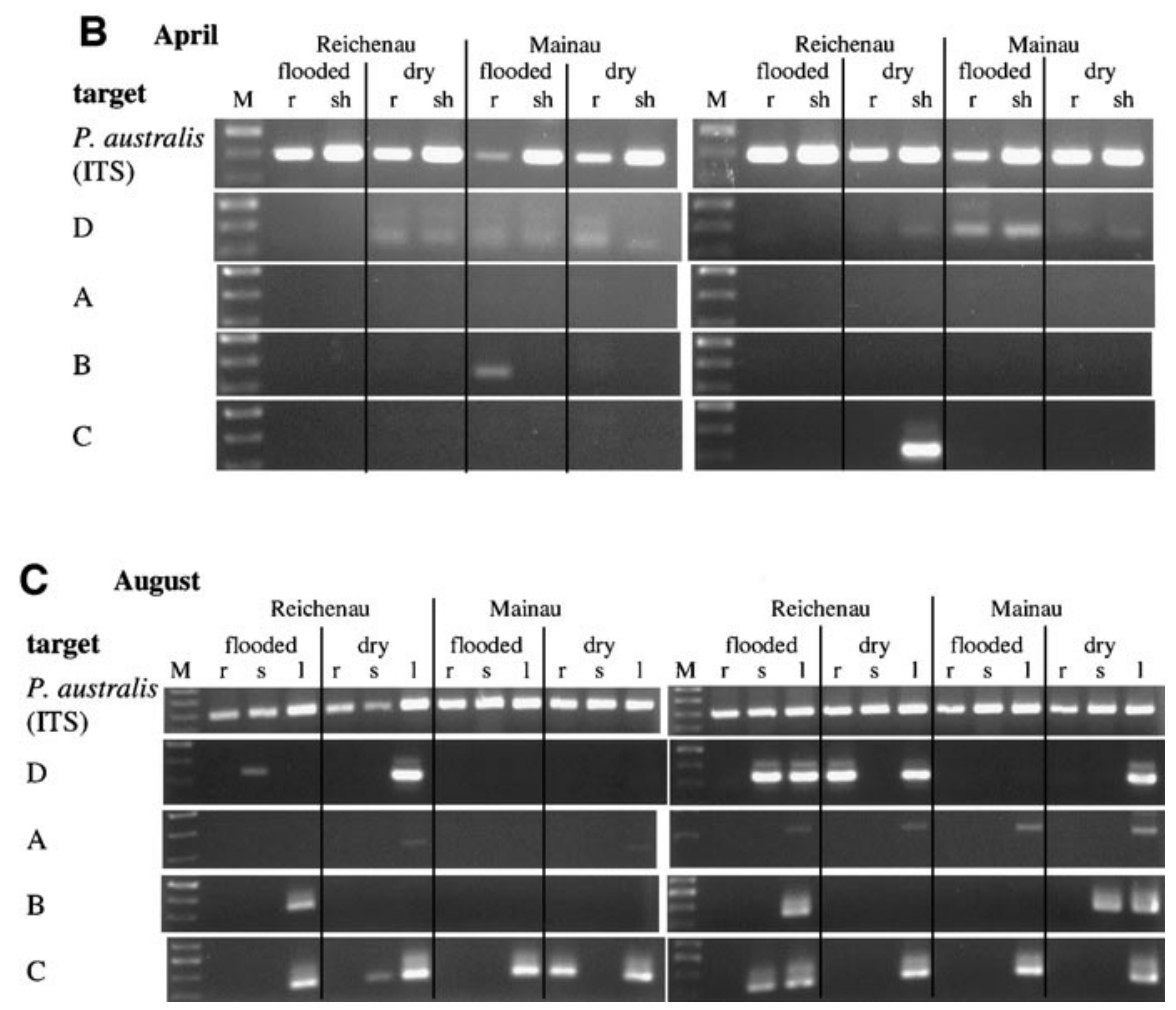

FIG. 6. Nested PCR detection of Cladosporium spp. in reed samples. (A) Specificity control with pure fungal genomic D NA as template. L anes $M$, 100-bp size marker; control, no D N A included; A13 to 315W, fungal genomic D N A from the respective strains (details in Table 1). Target, specifies the amplified DNA, i.e., Cladosporium spp., first step of nested PCR amplified actin gene fragments from all Cladosporia; A-D, second steps of nested PCR used as templates aliquots from the first step and amplified only actin gene subfragments from Cladosporium types $A$ to $D$ as represented by the indicated strains. (B) N ested PCR on reed DNA isolated from eight plants harvested in April from four sites at Lake Constance. Target, P. australis (ITS), amplification control of template D N A with host-directed ITS primers. Other targets as in (A). L anes M, 100-bp size marker; remaining lanes, PCR on template D N A isolated from two organs of reed ( $r$, root; sh, shoot) grown at the four indicated sampling sites. (C) N ested PCR on reed D NA isolated from eight plants harvested in August from four sites at Lake Constance. Targets, see (B). Lanes M, 100-bp size marker; remaining lanes, PCR on template D N A isolated from three organs of reed ( $r$, root; s, stem; I, leaf) grown at the four indicated sampling sites.

oxysporum type-into two subclades that differed only by one nucleotide. Interestingly, all strains with smooth conidial surfaces clustered together, as did all isolates with rough-walled conidia, thus reflecting a division among plant-associated Cladosporia. The rough-walled group was further distinguishable by the type of wall ornamentation. This was only possible with LTSEM at high resolution but again produced the same separations seen in the molecu- 
lar phylogeny. High-resolution LTSEM combined with molecular phylogeny also indicated inconsistencies with reference cultures that might have arisen from limitations of conventional light microscopy and the variability of asexual morphological structures often seen within this genus. D avid (1997) found that conidial surface ornamentations at the light microscopic level are not reliable enough to consistently distinguish species within Cladosporium; however, at least in the subset of species analyzed here, we found congruency of high-resolution SE M with molecular data. Whether this will hold true when analyzing representatives from all described species of this genus will have to await future studies. These studies may also elucidate whether the smooth conidial type is primitive and the ornamented type a derived character in this group of fungi. This is indicated since both $C$. fulvum ( $F$ ig. $1 F$ ) and M. graminicola (Duncan and Howard, 2000) have smooth conidia like those in our groups $A$ and $B$, whereas groups C and D and C. cladosporioides CBS 169.54 form a well-supported clade of fungi exhibiting distinctly ornamented conidia (see Fig. 4).

The value of using DNA sequences from intron-containing genes to study fungal evolution at the species/ population interface has been shown in several studies using different types of genes (Geiser et al., 1998; Carbone and Kohn, 1999; O 'D onnell et al., 2000). Alpha actin is an evolutionarily conserved component of the cytoskeleton and is encoded in filamentous ascomycetes by a singlecopy gene (Carbone and K ohn, 1999; Tarkka et al., 2000). A molecular phylogeny established from partial actin gene sequences produced the same overall topology as the ITS tree but differentiated the isolates at a higher resolution. Based on the morphological species concept, groups A and $B$ belong to the same species. In the context of a phylogenetic species concept, groups A and B appear as separate species. Actin data not only divided $A$ from $B$ but also showed further separations within the $A, B$, and $C$ groups. Phylogenies of additional protein-encoding genes could determine how many cryptic species are present within these groups. F or the moment, a conservative judgement would be that we have recovered at least four different species from reed.

The indistinguishable morphology and the close molecular similarity of the three CBS strains in ITS group A carrying different species designations (see F ig. 4) emphasizes the need to taxonomically reevaluate the whole genus on a broader scale. A multilocus genealogy supported by LTSEM studies involving more genes and more isolates originating from various geographical regions should be used to redefine species borders within Cladosporium.

\section{TABLE 5}

Kishino- $\mathrm{H}$ asegawa Test of Constrained and Unconstrained Trees from Combined ITS and Actin D atasets

\begin{tabular}{|c|c|c|c|c|}
\hline Tree $^{a}$ & $\begin{array}{c}\text { Tree } \\
\text { length }\end{array}$ & $\begin{array}{c}\text { SD of } \\
\text { difference }\end{array}$ & $t^{d}$ & $P^{e}$ \\
\hline M PT (unconstrained) & 206 & Best & Best & Best \\
\hline Constrained for location & $273(+67)$ & 11.02849 & 6.0752 & $<0.0001$ \\
\hline Constrained for habitat & $230(+24)$ & 7.1897 & 3.3412 & 0.0009 \\
\hline Constrained for organ & $266(+60)$ & 10.2615 & 5.8470 & $<0.0001$ \\
\hline
\end{tabular}

\footnotetext{
${ }^{a}$ The combined ITS/actin dataset was identical to that used in Fig. 4C except for the reference strains. Rearrangements to generate constrained trees concerned branches within each of the groups A-D shown in Fig. 4C.

${ }^{b} \mathrm{~N}$ umbers in parentheses show differences between the most parsimonious tree (MPT) and the respective constrained tree.

' $\mathrm{SD}$ of log likelihood.

d Pairwise t test.

e Probability of getting a more extreme t value under the null hypothesis of no difference between the compared trees by using the two-tailed test. All results are significant at $\mathrm{P}<0.05$.
}

LTSEM and molecular taxonomy based on ITS and actin sequences conclusively show that the reed-associated Cladosporia are not homogenous but fall into at least four species. We used three approaches, one statistical, one physiological, and one molecular, to investigate evidence for ecological specialization. F irst, we enforced topological constraints on the branches of a combined ITS/actin tree to simulate putative specialization according to sampling location, host habitat, and host organ. The trees comprised the same reed strains as those depicted in Fig. 4C but none of the reference cultures (data not shown). Rearrangements were in such a way that all isolates belonging to one ITS type remained in one cluster but terminal branches were exchanged accordingly. All of the constrained trees were significantly worse than the unconstrained most parsimonious tree as analyzed by the Kishino- $\mathrm{H}$ asegawa likelihood test $(\mathrm{P}>0.05)$ (Table 5). Therefore, the hypothesis that the phylogenetic separation seen within reed-associated Cladosporia is in concordance with host location, host habitat, and host organ can be rejected.

Second, we derived carbon catabolite fingerprints resulting from BIOLOG microtiter assays to investigate putative correlations with taxonomy at any level and/or with sampling details. Plant-associated fungi are obviously exposed to different carbon sources depending on the colonized host tissue. In addition, the spectrum of exudates from a given organ might vary with respect to habitat conditions. $\mathrm{F}$ ungi living in different habitats could therefore exhibit distinct carbon catabolite spectra- even 
within a species-as has been shown in a study with Fusarium compactum and related species (Talbot et al., 1996). The phylogeny derived from carbon catabolite spectra of reed-associated Cladosporia followed the morphological separations, i.e., again showed the $C$ and $D$ groups and the combined $A$ and $B$ groups. Whether the observed segregation of isolates is ecologically relevant is currently unclear since all species appeared to be present on all plant organs when both sampling records and PCR results are taken into account. The BIOL OG data also did not indicate physiologically specialized subpopulations within these species that would correlate with location, host habitat, or host organ. On the other hand, on a given organ different fungal species/populations might occupy different ecological microniches, for instance, the surface, the subcuticular space, or the apoplast.

Third, we used a nested PCR assay to distinguish the four different types of Cladosporium in DNA isolated from reeds growing at the same sites from where these fungi were initially recovered. By including samples harvested in April, we took into account that $P$. australis is a perennial grass that overwinters to emerge with young shoots every spring. These grow rapidly during the summer, reaching heights of $4 \mathrm{~m}$ at our locations. Three of the four Cladosporia were either missing or detected just once among 16 April samples analyzed. These belonged to ITS types A (C. oxysporum), B (Cladosporium sp.), and C (C. herbarum). $C$. oxysporum and $C$. herbarum are considered cosmopolitan (D avid, 1997) and were recovered from many different plant hosts, sometimes after surface sterilization procedures as we did (Petrini et al., 1992; Pelaez et al., 1998). On the other hand, the fourth type, i.e., Cladosporium sp. (ITS type D), was detected in several plants that had just emerged about 2 weeks prior. This might hint at a capacity to colonize reeds earlier than the others or at a systemic nature of this particular fungus. When analyzing plants harvested in August, at peak biomass, we found that these fungi are more common and colonized all host organs without clear preference for any sampling site, except for C. oxysporum (ITS type A). This fungus was detected by PCR only in leaf DNA, whereas sampling data also indicated its presence in other organs (Table 1), a difference that could have been caused by the fewer number of plants analyzed in the PCR assay.

Our results show that reed sympatrically hosts several species of Cladosporium that do not appear to be specialized for host organ or host habitat. If they would grow exactly at the same space and time, they might compete with each other. The analysis of cocolonization patterns did not reveal obvious antagonistic effects between the four types at the macroscopic level studied. A related study analyzed putative specialization of two sympatric species within the B otrytis cinerea species complex, which colonizes many plant species (Giraud et al., 1997). It was suggested that the more pathogenic species was a local adaptation in the Champagne region of $\mathrm{F}$ rance and that the more saprophytic species was a migrant. In addition to grapes, both were also detected later on several other host plants. Significant differences in their distribution correlated with host species but not with host organs or locations (Giraud et al., 1999). The genus Cladosporium comprises ubiquitous species (e.g., C. herbarum) and hostspecific species (e.g., C. colocasiae) (Ellis, 1971, 1976). Our data show that some of our isolates are very similar or even identical to reference cultures with respect to ITS and actin sequences, e.g., 6/97-4 and 6/97-44 to C. herbarum CBS 812.71 (see Fig. 4). Since the CBS strains originate from other host plants (see Table 2 ) it has to be concluded that the respective reed isolates do not appear to be specialized for this host. Other isolates are more distantly related to the reference cultures analyzed here, especially those included in the ITS groups B and D (see Fig. 4). It might be possible that these exhibit host preferences which could be analyzed by the nested PCR protocol developed during this work.

In summary, we have shown that fungi recovered from reed and initially assigned to the genus Cladosporium actually comprise at least four different species: $C$. herbarum, C. oxysporum, and two different Cladosporium spp. This finding highlights how diverse the reed-associated mycoflora might finally be, since Cladosporium was just 1 from at least 16 fungal genera found to be closely associated with P. australis (Wirsel et al., 2001). N one of several lines of investigation confirmed putative specialization of the different Cladosporia for host habitats or host organs. On the other hand, distinct temporal patterns of colonization or subtle specialization at the tissue level may characterize the different species. A combination of molecular and advanced visualization techniques such as in situ PCR might be able to increase the level of resolution necessary to address some of these questions.

\section{ACKNOWLEDGMENTS}

This project was financially supported by the SF B 454 from the D eutsche $\mathrm{F}$ orschungsgemeinschaft. We gratefully acknowledge J ohn $\mathrm{C}$. $D$ avid (CABI, U.K.) for the characterization of strains and Walter $G$ ams and Sybren de $\mathrm{H}$ oog for helpful comments on the manuscript. We thank 
M ichael E rnst, Ralf T. Voegele, Christine Struck, and M atthias $\mathrm{H}$ ahn for discussions.

\section{REFERENCES}

Carbone, I., and Kohn, L. M. 1999. A method for designing primer sets for speciation studies in filamentous ascomycetes. M ycologia 91: 553556.

Cunfer, B. M., and Ueng, P. P. 1999. Taxonomy and identification of Septoria and Stagonospora species of small grain cereals. Annu. Rev. Phytopathol. 37: 267-284.

Curtis, M. D., Gore, J., and Oliver, R. P. 1994. The phylogeny of the tomato leaf mould fungus Cladosporium fulvum syn. Fulvia fulva by analysis of rD NA sequences. Curr. Genet. 25: 318-322.

David, J. C. 1997. A Contribution to the Systematics of Cladosporium: Revision of the F ungi Previously Referred to $\mathrm{H}$ eterosporium. CAB Int., Oxon, U.K.

De Vries, G. A. 1967. Contribution to the Knowledge of the Genus Cladosporium Link ex. Fr. Cramer, Lehre, Germany.

Dobranic, J. K., and Zak, J. C. 1999. A microtiter plate procedure for evaluating fungal functional diversity. Mycologia 91: 756-765.

D ugan, F. M ., and Roberts, R. G. 1994. M orphological and reproductive aspects of Cladosporium macrocarpum and $C$. herbarum from bing cherry fruits. M ycotaxon 52: 513-522.

D uncan, K. E., and Howard, R. J. 2000. Cytological analysis of wheat infection by the leaf blotch pathogen Mycosphaerella graminicola. M ycol. Res. 104: 1074-1082.

Ellis, M. B. 1971. Dematiaceous Hyphomycetes. CAB Int., Kew, UK.

Ellis, M. B. 1976. More Dematiaceous Hyphomycetes. CAB Int., Kew, UK.

Gardes, M., and Bruns, T. D. 1993. ITS primers with enhanced specificity for Basidiomycetes-Application to the identification of mycorrhizae and rusts. Mol. Ecol. 2: 113-118.

Geiser, D. M., Pitt, J. I., and Taylor, J. W. 1998. Cryptic speciation and recombination in the aflatoxin-producing fungus Aspergillus flavus. Proc. Natl. Acad. Sci. USA 95: 388-393.

Giraud, T., F ortini, D., Levis, C., L amarque, P., Leroux, P., LoBuglio, K. F., and Brygoo, Y. 1999. Two sibling species of the Botrytis cinerea complex, transposa and vacuma, are found in sympatry on numerous host plants. Phytopathology 89: 967-973.

Giraud, T., F ortini, D ., L evis, C., Leroux, P., and Brygoo, Y. 1997. RF LP markers show genetic recombination in Botryotinia fuckeliana (Botrytis cinerea) and transposable elements reveal two sympatric species. Mol. Biol. Evol. 14: 1177-1185.
Harrington, T. C., Steimel, J., Workneh, F., and Yang, X. B. 2000. $M$ olecular identification of fungi associated with vascular discoloration of soybean in the North Central United States. Plant Disease 84: 83- 89.

M asclaux, F., Guého, E., De Hoog, G. S., and Christen, R. 1995. Phylogenetic relationships of human-pathogenic Cladosporium (Xylohypha) species inferred from partial LS rRN A sequences. J. M ed. Vet. M ycol. 33: 327-338.

M oricca, S., Ragazzi, A., and M itchelson, K. R. 1999. Molecular and conventional detection and identification of Cladosporium tenuissimum on two-needle pine rust aeciospores. Can. J. Bot. 77: 339-347.

O'D onnell, K., Kistler, H. C., Tacke, B. K., and Casper, H. H. 2000. Gene genealogies reveal global phylogeographic structure and reproductive isolation among lineages of Fusarium graminearum, the fungus causing wheat scab. Proc. Natl. Acad. Sci. USA 97: 7905-7910.

Pelaez, F., Collado, J., Arenal, F., Basilio, A., Cabello, A., M atas, M. T. D., Garcia, J. B., D elVal, A. G., Gonzalez, V., G orrochategui, J., H ernandez, P., M artin, I., Platas, G., and Vicente, F . 1998. E ndophytic fungi from plants living on gypsum soils as a source of secondary metabolites with antimicrobial activity. Mycol. Res. 102: 755-761.

Petrini, O., Sieber, T. N., Toti, L., and Viret, O. 1992. E cology, metabolite production, and substrate utilization in endophytic fungi. $\mathrm{Nat}$. Toxins 1: 185-196.

Swofford, D. L. 2000. Phylogenetic Analysis Using Parsimony (* and Other M ethods), Sinauer, Sunderland, MA.

Talbot, N. J., Vincent, P., and Wildman, H. G. 1996. The influence of genotype and environment on the physiological and metabolic diversity of Fusarium compactum. Fungal Genet. Biol. 20: 254-267.

Tarkka, M. T., Vasara, R., Gorfer, M., and Raudaskoski, M. 2000. M olecular characterization of actin genes from homobasidiomycetes: Two different actin genes from Schizophyllum commune and Suillus bovinus. Gene 251: 27-35.

Untereiner, W. A., and Naveau, F. A. 1999. M olecular systematics of the $\mathrm{H}$ erpotrichiellaceae with an assessment of the phylogenetic positions of Exophiala dermatitidis and Phialophora americana. M ycologia 91: 67- 83.

White, T. J., Bruns, T., Lee, S., and Taylor, J. 1990. Amplification and direct sequencing of fungal ribosomal R N A genes for phylogenetics. In PCR Protocols: A Guide to Methods and Applications (M. A. Innis, D. H. Gelfand, J. J. Sninsky, and T. J. White, Eds.), pp. 315-322, Academic Press, New York.

Wirsel, S. G. R., Leibinger, W., E rnst, M., and M endgen, K. 2001. Genetic diversity of fungi closely associated with common reed. New Phytol. 149: 589-598.

Wosten, H . A., and de Vocht, M . L. 2000. H ydrophobins, the fungal coat unravelled. Biochim. Biophys. Acta 1469: 79-86. 